\title{
Study on Inorganic Modification of Damping Capacity of Polyurethane Materials for Building
}

\author{
Zhou Feng $^{1,2}$ Gan Jianjun ${ }^{3 *}$ Du Xin ${ }^{2}$ Cui Ligang ${ }^{2}$ \\ ${ }^{1}$ Key Laboratory On Infrastructure Safety Of Water Conservancy And Civil Engineering, Nanchang Institute Of Technology, \\ Nanchang, China,330099 \\ ${ }^{2}$ School Of Civil And Architectural Engineering, Nanchang Institute Of Technology, 330099 Nanchang, China \\ ${ }^{3}$ School Of Water Conservancy And Ecological Engineering, Nanchang Institute Of Technology, 330099
}

\begin{abstract}
As a kind of passive control device, viscoelastic damper has been successfully applied to all kinds of engineering structures. However, the viscoelastic material in viscoelastic dampers is mainly based on rubber. Therefore, in this thesis, the viscoelastic material is the main line of study. Different viscoelastic material formulas are being used to make the corresponding damper and study the correlation performance of such damper in the low frequency region. In this thesis, we mainly study the polyurethane elastomer material, but simplex polyurethane elastomer materials have low damping and cannot achieve the effect of building damping, so it's necessary to study the modification. In this experiment, four kinds of inorganic fillers, mica powder, zinc oxide, silica and glass fiber were used to modify the polyurethane elastomer. Its damping performance then is tested by a dynamic load testing machine in a low frequency region of 0.1 $\mathrm{Hz}-1.0 \mathrm{~Hz}$.
\end{abstract}

\section{Introduction}

According to relevant engineering examples, using viscoelastic damper can achieve anti-seismic results, thereby enhancing the safety and comfort of the structure. The current base material used in viscoelastic dampers are mainly rubber, however, it has defects such as causing environmental pollution, therefore, this thesis uses polyurethane elastomer viscoelastic materials in replacement of rubber materials.

This thesis mainly introduces the study of several inorganic filler modified polyurethane elastomer. A group of researchers from Marine chemical research institute co. LTD. led by Huang Weibo ${ }^{[1]}$ used mica powder to modify the polyurethane elastomer. Their result shows that using flake mica powder can improve the energy dissipation factor and the performance of viscoelastic materials significantly. A research group from SJTU led by Guo Chuangqi ${ }^{[2]}$ used Nano zinc oxide whiskers to modify the PU material and studied the impact of different whisker contents on the PU materials' damping characteristics. They found that the energy storage modulus of the PU material is inversely proportional to the whisker content. In addition to that, with the increase of whisker content, the damping coefficient is greatly increased, and the maximum value is obtained when the quality fraction of the whisker is at $2 \%$. A group of researchers from QUST led by Xu Jinpeng ${ }^{[3]}$ synthesized modified silica/polyurethane elastomer composite. Their results indicate that modified
Nano-silica can improve polyurethane elastomers' mechanical properties and damping capacity as well as widening its temperature range. S.H.Kim ${ }^{[4]}$, along with other researchers from abroad have conducted the same experiment and obtained similar results.

The above analysis shows that in China, the studies on energy dissipation and shock absorption of the viscoelasticity of polyurethane mostly concentrate in the high frequency region $(10 \mathrm{~Hz} \sim$ several hundred $\mathrm{Hz})$, whereas this thesis mainly focuses on low frequency region damping capacities in order to meet the shock absorption purpose of buildings. Four kinds of inorganic fillers are being added: mica powder, zinc oxide, silica and glass fiber, to modify the elastomer's damping capacities and mechanical properties, so as to make viscoelastic dampers. Then its damping and mechanical properties is being assessed through the hysteresis curve obtained from the dynamic load testing machine.

\section{Experimental Part}

\subsection{Raw Materials And Instruments}

Polypropylene oxide glycol (PPG), industrial grade, from Usolf chemical technology co. LTD, Shandong. Toluene diisocyanate (TDI), analytically pure, from Bayer AG, Germany. Trimethylol Propane (TMP), industrial grade, from Bodi chemical co. LTD, Tianjin. Mica powder, zinc oxide, and silica are all of nanoscale, glass fiber $(3 \mathrm{~mm}$ in length) are all commercially available. The releasing 
agent is silicone oil, industrial grade, from Skyhawk industry and trade co. LTD, Dongguan. Adhesive is Chemlok 218, industrial grade, from Lord Chemical (Shanghai) co. LTD. 50T flat vulcanizing machine, from Zhengshi hydraulic machinery co. LTD, Hebei. Self-made molds are shown in figure 1, 2, and 3:

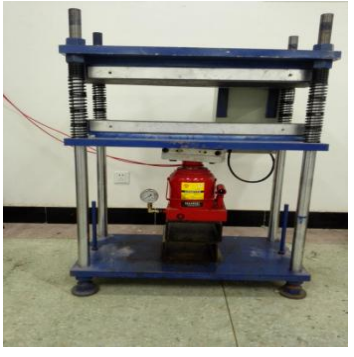

Fig 1 50T Flat Vulcanizing Machine

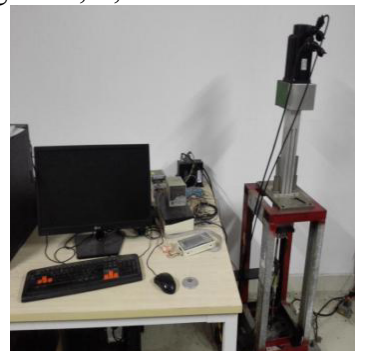

Fig 2 Dynamic Load Testing Machine

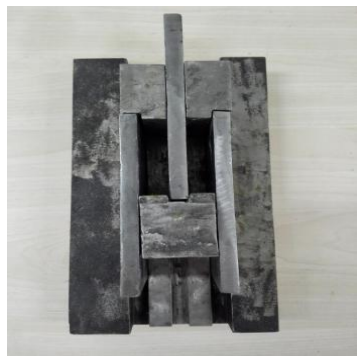

Fig 3 Mold

\subsection{Testing Methods}

The specific synthesizing methods are as follows: first, weigh and take the calculated amount of PPT-1500 together with inorganic fillers, mix and stir to conduct 30 mins of ultrasonic dispersion, then dehydrate the mixture under $110^{\circ} \mathrm{Cin}$ an electric vacuum drying oven for 2 hours; after cooling down to about $50^{\circ} \mathrm{C}$ in a flask with three necks add in the calculated amount of TDI, gently heating up to $80^{\circ} \mathrm{C} \pm 5^{\circ} \mathrm{C}$, let it react for $2-3 \mathrm{~h}$ to obtain polyurethane prepolymer, measure its -NCO content, then blend in the calculated chain extender, pour the mixture into the mold after conducting defoaming treatment. Before giving pressure treatment on a vulcanizing machine for another $5 \mathrm{~h}$, the mixture has to be solidified for $3 \mathrm{~h}$ under $110^{\circ} \mathrm{C}$ and then being cured under $110^{\circ} \mathrm{C}$ after demolding for $4 \mathrm{~h}$ to get the final modified elastomer.

\subsection{Performance Test}

Use a dynamic load testing machine to test the damping capacity of the viscoelastic damper-made via the above methods - in low frequency regions $(0.1 \mathrm{~Hz}-1.0 \mathrm{~Hz})$. By means of displacement control and load with sine wave to obtain the load-displacement hysteresis curve and calculate the correlation damping coefficient. The design parameters of the viscoelastic damper in this experiment are shown in Table 1:
Table 1 Design Parameters For Viscoelastic Dampers

\begin{tabular}{lllll}
\hline $\begin{array}{l}\text { Base } \\
\text { Material }\end{array}$ & $\begin{array}{c}\text { Viscoelast } \\
\text { ic Region } \\
\left(\mathrm{mm}^{2}\right)\end{array}$ & $\begin{array}{l}\text { Viscoelast } \\
\text { ic Layer } \\
\text { Thickness } \\
(\mathrm{mm})\end{array}$ & $\begin{array}{l}\text { Steel Plate } \\
\text { Thickness } \\
(\mathrm{mm})\end{array}$ & $\begin{array}{l}\text { Number } \\
\text { Of } \\
\text { Viscoelasti } \\
\text { c Layer }\end{array}$ \\
\hline $\begin{array}{l}\text { Polyuretha } \\
\text { ne }\end{array}$ & 2500 & 15 & 10 & 2 \\
\hline
\end{tabular}

The equivalent damping ratio = Energy dissipated in a cycle $/ 4 \pi$ times $^{[5]}$ the strain energy stored when the system produces maximum deformation, which is an important index for measuring the damping of viscoelastic materials. It can be obtained by the viscoelastic materials' correlation formula.

\section{Experiment And Discussion}

\subsection{Polyurethane Elastomer Without Inorganic Fillers}

Conducting trials via the dynamic load testing machine and the hysteresis curve of polyurethane elastomer without inorganic fillers is shown in figure 4

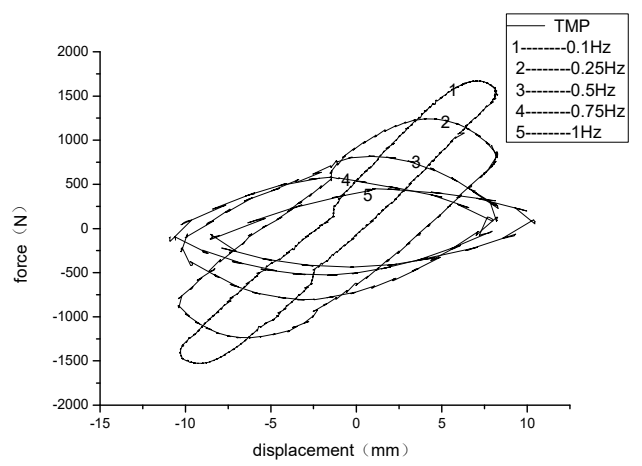

Fig 4 Hysteresis Curve Of Unfilled Elastomers

Through figure 4 and according to the correlation coefficient calculation formula of the viscoelastic materials, the results are shown in Table 4:

Table 4 Unfilled Elastomer Damping Correlation Coefficient

\begin{tabular}{llll}
\hline $\begin{array}{l}\text { Displacement } \\
\text { Amplitude } \\
(\mathrm{mm})\end{array}$ & $\begin{array}{c}\text { Frequency } \\
(\mathrm{Hz})\end{array}$ & $\begin{array}{l}\text { Equivalent } \\
\text { Damping Ratio }\end{array}$ & $\begin{array}{l}\text { Hysteresis } \\
\text { Curve } \\
\text { Region }(\mathrm{J})\end{array}$ \\
\hline & 0.1 & 0.11 & 10.06 \\
10 & 0.25 & 0.43 & 20.40 \\
& 0.5 & 1.53 & 19.03 \\
& 0.75 & 2.86 & 13.58 \\
& 1.0 & 2.47 & 10.79 \\
\hline
\end{tabular}


Table 5 The Corresponding Maximum Force Of The Unweighted Elastomer At Each Frequency Stage

\begin{tabular}{lc}
\hline Frequency $(\mathrm{Hz})$ & $\begin{array}{c}\text { Corresponding } \\
\text { Maximum Force }(\mathrm{N})\end{array}$ \\
\hline 0.1 & 1600 \\
0.25 & 1240 \\
0.5 & 820 \\
0.75 & 560 \\
1.0 & 450 \\
\hline
\end{tabular}

\subsection{Mica Powder Modified Polyurethane Elastomer}

Table 6 Mica Powder Modified Polyurethane Elastomer Damping Correlation Coefficient

\begin{tabular}{llll}
\hline $\begin{array}{l}\text { Displacement } \\
\text { Amplitude } \\
(\mathrm{mm})\end{array}$ & $\begin{array}{c}\text { Frequency } \\
(\mathrm{Hz})\end{array}$ & $\begin{array}{l}\text { Equivalent } \\
\text { Damping Ratio }\end{array}$ & $\begin{array}{l}\text { Hysteresis } \\
\text { Curve } \\
\text { Region }(\mathrm{J})\end{array}$ \\
\hline & 0.1 & 0.09 & 9.41 \\
& 0.25 & 0.37 & 19.09 \\
10 & 0.5 & 2.06 & 18.05 \\
& 0.75 & 4.86 & 13.09 \\
& 1.0 & 1.82 & 10.41 \\
\hline
\end{tabular}

Table 7 The Corresponding Maximum Force At Each Frequency Stage Of The Mica Powder Modified Elastomer

\begin{tabular}{lc}
\hline Frequency $(\mathrm{Hz})$ & $\begin{array}{c}\text { Corresponding } \\
\text { Maximum Force }(\mathrm{N})\end{array}$ \\
\hline 0.1 & 1544 \\
0.25 & 1181 \\
0.5 & 773 \\
0.75 & 529 \\
1.0 & 428 \\
\hline
\end{tabular}

\subsection{Zinc Oxide Modified Polyurethane Elastomer}

Table 8 Zinc Oxide Modified Polyurethane Elastomer Damping Correlation Coefficient

\begin{tabular}{llll}
\hline $\begin{array}{l}\text { Displacement } \\
\begin{array}{c}\text { Amplitude } \\
(\mathrm{mm})\end{array}\end{array}$ & $\begin{array}{c}\text { Frequency } \\
(\mathrm{Hz})\end{array}$ & $\begin{array}{l}\text { Equivalent } \\
\text { Damping Ratio }\end{array}$ & $\begin{array}{l}\text { Hysteresis } \\
\text { Curve } \\
\text { Region }(\mathrm{J})\end{array}$ \\
\hline & 0.1 & 0.08 & 6.65 \\
& 0.25 & 0.41 & 14.03 \\
10 & 0.5 & 1.48 & 13.36 \\
& 0.75 & 2.78 & 9.72 \\
& 1.0 & 1.34 & 7.61
\end{tabular}

Table 9 The Corresponding Maximum Force At Each Frequency Stage Of The Zinc Oxide Modified Elastomer

\begin{tabular}{lll}
\hline Frequency $(\mathrm{Hz})$ & $\begin{array}{l}\text { Corresponding } \\
\text { Force }(\mathrm{N})\end{array}$ & Maximum \\
\hline 0.1 & 1216 & \\
0.25 & 912 & \\
0.5 & 593 & \\
0.75 & 411 & \\
1.0 & 328 \\
\hline
\end{tabular}

\subsection{Silica Modified Polyurethane Elastomer}

Table 10 Silica Modified Polyurethane Elastomer Damping Correlation Coefficient

\begin{tabular}{llll}
\hline $\begin{array}{l}\text { Displacem } \\
\text { ent } \\
\begin{array}{l}\text { Amplitude } \\
(\mathrm{mm})\end{array}\end{array}$ & $\begin{array}{l}\text { Frequency } \\
(\mathrm{Hz})\end{array}$ & $\begin{array}{l}\text { Equivalent } \\
\text { Damping Ratio }\end{array}$ & $\begin{array}{l}\text { Hysteresi } \\
\text { s Curve } \\
\text { Region } \\
(\mathrm{J})\end{array}$ \\
\hline & 0.1 & 0.08 & 5.71 \\
& 0.25 & 0.38 & 14.27 \\
10 & 0.5 & 1.17 & 14.96 \\
& 0.75 & 2.32 & 11.41 \\
& 1.0 & 1.25 & 9.05
\end{tabular}

Table 11 The Corresponding Maximum Force At Each Frequency Stage Of The Silica Modified Elastomer

\begin{tabular}{lll}
\hline Frequency $(\mathrm{Hz})$ & $\begin{array}{l}\text { Corresponding } \\
\text { Force }(\mathrm{N})\end{array}$ \\
\hline 0.1 & 1233 \\
0.25 & 979 \\
0.5 & 660 \\
0.75 & 461 \\
1.0 & 369 \\
\hline
\end{tabular}

\subsection{Glass Fiber Modified Polyurethane Elastomer}

Table 12 Glass Fiber Modified Polyurethane Elastomer Damping Correlation Coefficient

\begin{tabular}{llll}
\hline $\begin{array}{l}\text { Displacem } \\
\text { ent } \\
\begin{array}{c}\text { Amplitude } \\
(\mathrm{mm})\end{array}\end{array}$ & $\begin{array}{l}\text { Frequency } \\
(\mathrm{Hz})\end{array}$ & $\begin{array}{l}\text { Equivalent } \\
\text { Damping Ratio }\end{array}$ & $\begin{array}{l}\text { Hysteresis } \\
\text { Curve } \\
\text { Region }(\mathrm{J})\end{array}$ \\
\hline & 0.1 & 0.03 & 7.01 \\
& 0.25 & 0.29 & 19.28 \\
10 & 0.5 & 0.93 & 20.14 \\
& 0.75 & 1.86 & 15.16 \\
& 1.0 & 2.16 & 11.93
\end{tabular}

Table 13 The Corresponding Maximum Force At Each

Frequency Stage Of The Glass Fiber Modified Elastomer

\begin{tabular}{lc}
\hline Frequency $(\mathrm{Hz})$ & $\begin{array}{c}\text { Corresponding Maximum } \\
\text { Force }(\mathrm{N})\end{array}$ \\
\hline 0.1 & 1824 \\
0.25 & 1392 \\
0.5 & 913 \\
0.75 & 620 \\
1.0 & 504 \\
\hline
\end{tabular}

\section{Conclusions}

1) Mica powder modified polyurethane elastomer's average equivalent damping ratio improved by $24.3 \%$, average hysteresis curve area reduced by $5.1 \%$ and average corresponding force decreased by $4.6 \%$ in frequency stages between $0.1 \mathrm{~Hz}-1.0 \mathrm{~Hz}$.

2) Zinc oxide modified polyurethane elastomer's average equivalent damping ratio decreased by $17.6 \%$, average hysteresis curve area reduced by $30.5 \%$ and average corresponding force dropped by $25.9 \%$ in frequency stages between $0.1 \mathrm{~Hz}-1.0 \mathrm{~Hz}$. 
3) Nanosilica modified polyurethane elastomer's average equivalent damping ratio decreased by $29.7 \%$, average hysteresis curve area reduced by $25.0 \%$ and average corresponding force dropped by $18.6 \%$ in frequency stages between $0.1 \mathrm{~Hz}-1.0 \mathrm{~Hz}$.

4) Glass fiber modified polyurethane elastomer's average equivalent damping ratio decreased by $29.1 \%$, average hysteresis curve area reduced by $0.5 \%$ and average corresponding force increased by $12.5 \%$ in frequency stages between $0.1 \mathrm{~Hz}-1.0 \mathrm{~Hz}$.

Judging from the experimental data, the polyurethane elastomer damper is not full enough in the low frequency region of $0.1 \mathrm{~Hz}$, this may be related to the small molecular weight (only a few thousand) of the polyurethane elastomer itself. Whereas the rubber viscoelastic damper usually has a molecular weight of above 100,000 by using polyblend of solid materials.

The adding of inorganic fillers cannot result in a substantial increase of the damping capacity of polyurethane elastomers in the low frequency region between $0.1 \sim 1.0 \mathrm{~Hz}$. Meanwhile, in consideration of possible impacts of unactivated inorganic fillers' surface, further research will be conducted.

At the same time, it can be found via the hysteresis curve, that the damping curve of polyurethane viscoelastic materials falls in between the rubber viscoelastic and liquid viscous dampers. In low frequency regions, it is similar to the rubber viscoelastic damper, distributed in quadrant one and three, while in high frequency regions, it resembles the liquid viscous damper, evenly distributed in all four quadrants. So, when measuring the damping characteristics, this thesis uses equivalent damping ratio for low frequency regions and energy dissipation area integral for high frequency regions.

\section{References}

1. Huang Weibo, Zhan Fengchang. Study on dynamic mechanical properties of polyurethane damping materials.[J] Polymeric Materials Science and Engineering, 1992, 4(4): 42-44.

2. Guo Chuangqi, Zhu Qiren, Zheng Zhen, etc. Dynamic mechanical properties of polyurethane/Nano zinc oxide composites.[C] 2005 National high polymer academic paper conference, 2005: 487.

3. Xu Jinpeng, Sun Shaojie, Xin Haobo, Ding Naixiu. Synthesis and characterization of modified nano- $\mathrm{SiO}_{2} /$ polyurethane elastomer composites.[J] China Elastomerics, 2017, 27(01):10-13.

4. Kim S H, et al. Journal of Materials Science, 2010, 45(10):2675-2680.

5. Clough R W, Penzien J. Dynamics of Structures[M]. McGraw-Hill Inc, New York,1975. 